Agrotrópica 33(1): 29 - 38. 2021.

Centro de Pesquisas do Cacau, Ilhéus, Bahia, Brasil

\title{
AVALIAÇÃO DO USO DE CERA DE CARNAÚBA NA CONSERVAÇÃO PÓS- COLHEITA DE FRUTOS DE Passiflora cincinnata CV. BRS SERTÃO FORTE
}

\author{
Maria Madalena Rinaldi, Alexei de Campos Dianese, Ana Maria Costa \\ Empresa Brasileira de Pesquisa Agropecuária /Embrapa Cerrados (CPAC) - BR 020, km 18, Rodovia Brasília-Fortaleza, \\ Caixa Postal 08223, 73310-970, Planaltina, DF, Brasil.madalena.rinaldi@embrapa.br, alexei.dianese@embrapa.br, ana- \\ costa@embrapa.br
}

Objetivou-se avaliar a conservação pós-colheita de frutos de Passiflora cincinnata cultivar BRS Sertão Forte, revestidos com cera de carnaúba na concentração de $18 \%$ e armazenados sob condição ambiente $\left(25^{\circ} \mathrm{C}\right.$ e umidade relativa de $66 \%$ ) e refrigerada $\left(10^{\circ} \mathrm{C}\right.$ e umidade relativa de $\left.85 \%\right)$. Os frutos foram mantidos nestas condições por 98 dias, sendo avaliados aos zero, 30, 45, 60,75 e 98 dias quanto a incidência de patógenos fúngicos, perda de massa fresca, cor ( $\mathrm{L}^{*}, \mathrm{a}^{*}, \mathrm{~b}^{*}$, incremento no escurecimento, croma e ângulo hue), textura, $\mathrm{pH}$, acidez titulável, sólidos solúveis e Ratio. Não ocorreu alteração significativa da cor dos frutos durante o armazenamento. Frutos mantidos em condição ambiente tiveram alta incidência de fungos durante o armazenamento. Frutos de $P$. cincinnata podem ser mantidos em câmara fria na temperatura de $10^{\circ} \mathrm{C}$ e umidade relativa de $85 \%$ por 98 dias. Em condição de temperatura e umidade relativa ambiente a vida útil dos frutos é de no máximo 30 dias. A utilização da cera de carnaúba na concentração de $18 \%$ não aumenta a vida útil dos frutos de $P$. cincinnata. Além disso, não há eficácia da cera de carnaúba quanto à prevenção de infecções fúngicas, não justificando a sua utilização.

Palavras-chave: armazenamento, temperatura, vida útil, físico-química, textura.

Post-harvest conservation of Passiflora cincinnata fruits cv. BRS Sertão Forte with carnauba wax. The objective was to evaluate the postharvest conservation of Passiflora cincinnata fruits cultivar BRS Sertão Forte, coated with carnauba wax at a concentration of $18 \%$ and stored under ambient conditions $\left(25^{\circ} \mathrm{C}\right.$ and $66 \%$ relative humidity) and refrigerated $\left(10^{\circ} \mathrm{C}\right.$ and relative humidity of $\left.85 \%\right)$. The fruits were kept in these conditions for 98 days, being evaluated at zero, 30, 45, 60, 75 and 98 days for the incidence of fungal pathogens, loss of fresh weight, color ( $\mathrm{L}^{*}, \mathrm{a} *, \mathrm{~b} *$, increase in browning, chroma and hue angle), texture, $\mathrm{pH}$, titratable acidity, soluble solids and ratio. There was no significant change in the color of the fruits during storage. Fruits kept in ambient condition had a high incidence of fungi during storage. $P$. cincinnata fruits can be kept in a cold chamber at a temperature of $10^{\circ} \mathrm{C}$ and a relative humidity of $85 \%$ for 98 days. In conditions of temperature and relative humidity, the shelf-life of the fruits is a maximum of 30 days. The use of carnauba wax at a concentration of $18 \%$ does not increase the shelf-life of $P$. cincinnata fruits. In addition, there is no efficacy of carnauba wax in preventing fungal infections, not justifying its use.

Key words: storage, temperature, shelf-life, physic-chemical, texture. 


\section{Introdução}

O Brasil destaca-se como o maior produtor e exportador mundial de frutos de maracujá, devido às condições edafoclimáticas favoráveis ao bom desenvolvimento da cultura (Botelho et al., 2019). O maracujá do mato (Passiflora cincinnata Mast.), é um fruto nativo da caatinga e é resistente a pragas e doenças que comumente acometem o maracujá azedo (Passiflora edulis Sims). Normalmente, é explorado de forma extrativista, e é utilizado para a agregação de valor com a industrialização em pequenas fábricas (Novais Júnior et al., 2020).

A espécie Passiflora cincinnata Mast. vem se popularizando no mercado pelo sabor diferenciado dos seus frutos. É comercializada in natura em feiras de pequeno porte, principalmente em Pernambuco, Minas Gerais e na Bahia, e é utilizada para preparação de geleias por pequenas cooperativas locais (Carmo et al., 2017). Essa espécie apresenta grande potencial comercial, inclusive no mercado internacional, destacando-se seu uso na agroindústria, sua produtividade e tolerância ao estresse hídrico (Faleiro et al., 2017).

A cultivar BRS Sertão Forte foi obtida pelo melhoramento genético da espécie $P$. cincinnata realizado em uma parceria da Embrapa Semiárido com a Embrapa Cerrados. Os frutos apresentam forma arredondada e, quando maduros, têm casca com coloração predominantemente verde (Araújo et al., 2019).

A cera de carnaúba, uma palmeira brasileira (Copernicia prunifera), tem sido usada como revestimento em frutas e hortaliças, conferindo brilho e evitando as perdas por transpiração (Hagenmaier \& Baker, 1994). O produto não é tóxico, pode ser consumido nos frutos com casca e é facilmente removida com água (Hagenmaier \& Baker, 1994). Blum et al. (2008) relataram que a imersão de frutos de caqui (Diospyrus kaki) em solução com 12,5\% de cera de carnaúba foi eficiente na manutenção do ácido ascórbico e da firmeza dos tecidos, permitindo o armazenamento por até 49 dias. Mota et al. (2003) e Mota et al. (2006) indicaram que o uso de cera de carnaúba reduziu, significativamente, a perda de massa fresca e o murchamento em frutos de maracujáamarelo (Passiflora edulis) armazenados à temperatura e umidade relativa ambiente. Silva, Lacerda e Vieites (1999) verificaram que frutos de $P$. alata imersos em cera de carnaúba, e mantidos à temperatura de $9{ }^{\circ} \mathrm{C}$ e umidade relativa entre 85 e $90 \%$, também tiveram menos perda de massa fresca e murchamento quando comparados à testemunha. Já Rinaldi et al. (2019a) reportaram que frutos de P. alata revestidos por uma solução com $18 \%$ de cera de carnaúba e armazenados em temperatura ambiente apresentaram parâmetros fisiológicos, como $\mathrm{pH}$ e perda de massa fresca, inferiores aos frutos embalados em filmes plásticos, além de um percentual de frutos infestados por antracnose superior ao tratamento controle.

A utilização de refrigeração na conservação de frutos do maracujazeiro já é recomendada para as espécies $P$. setacea, P. alata e $P$. edulis, pois proporciona um maior tempo de prateleira, além de preservar vários parâmetros fisiológicos importantes, como, por exemplo, a textura da casca, além de reduzir a infestação por agentes fúngicos (Rinaldi et al., 2019a; Rinaldi et al., 2017c; Rotili et al., 2013a; Junqueira et al., 2003). No entanto, não existem informações sobre o efeito desse tipo de armazenamento em $P$. cincinnata.

Assim, o objetivo do trabalho foi avaliar a conservação pós-colheita de frutos de maracujá $P$. cincinnata cv. BRS Sertão Forte revestidos com cera de carnaúba e armazenados sob condição ambiente e refrigerada.

\section{Material e Métodos}

Utilizaram-se frutos da espécie $P$. cincinnata cv. BRS SF (nome comercial BRS Sertão Forte) oriundos do campo experimental da Embrapa Cerrados $\left(15^{\circ} 36^{\prime} 13.02^{\prime \prime} \mathrm{S} ; 4^{\circ} 43^{\prime} 17.34^{\prime \prime O}\right)$ a uma altitude de aproximadamente $1050 \mathrm{~m}$, em Planaltina, Distrito Federal em Latossolo Vermelho distrófico, textura argilosa (45\% argila) (Lima et al., 2014). Os frutos foram colhidos com aproximadamente 100 dias após a antese. A colheita foi realizada manualmente, com o auxílio de tesoura para o corte do pedúnculo, e os frutos foram resfriados em câmara fria por 12 horas $\left(10 \pm 1{ }^{\circ} \mathrm{C}\right.$ e $85 \%$ de umidade relativa), lavados em água corrente com posterior secagem em papel toalha, e submetidos ou não ao processo de revestimento 
manual de forma a cobrir toda a superfície dos frutos com uma fina camada de cera de carnaúba na concentração de $18 \%$, fornecida pela Aruá - empresa de tecnologia de pós-colheita (São Paulo - SP). O experimento consistiu nos seguintes tratamentos: (i) Frutos de $P$. cincinnata apenas lavados em água corrente com posterior secagem em papel toalha, armazenados sob condição ambiente na temperatura de $25{ }^{\circ} \mathrm{C}$ e umidade relativa de $66 \%$ - Testemunha Ambiente (TA); (ii) Frutos de P. cincinnata apenas lavados em água corrente com posterior secagem em papel toalha, armazenados em câmara fria na temperatura de $10{ }^{\circ} \mathrm{C} \pm 1{ }^{\circ} \mathrm{C}$ e umidade relativa de 85\% - Testemunha Refrigerado (TR); (iii) Frutos de P. cincinnata lavados em água corrente com posterior secagem em papel toalha, revestidos manualmente com cera de carnaúba a $18 \%$ e armazenados sob condição ambiente na temperatura de $25^{\circ} \mathrm{C}$ e umidade relativa de 66\% - Cera Ambiente (CA); (iv) Frutos de $P$. cincinnata lavados em água corrente com posterior secagem em papel toalha, revestidos manualmente com cera de carnaúba a $18 \%$ e armazenados em câmara fria na temperatura de $10{ }^{\circ} \mathrm{C} \pm 1{ }^{\circ} \mathrm{C}$ e umidade relativa de $85 \%$ - Cera Refrigerado (CR). Todos os tratamentos foram armazenados por 98 dias.

No início do experimento, os frutos foram pesados e tiveram seus diâmetros maiores (distância entre o ápice e o inicio do pedúnculo do fruto) e diâmetros menores determinados. Também foi obtida a massa da polpa mais sementes, massa da polpa, sementes e casca. No início do armazenamento (dia zero), aos 30, 45, 60, 75 e 98 dias de armazenamento, os frutos dos diferentes tratamentos foram submetidos à análise de perda de massa fresca, cor, textura, $\mathrm{pH}$, acidez titulável, sólidos solúveis e Ratio. A análise de perda de massa fresca foi obtida pela massa inicial do produto no início do armazenamento em relação à massa no final do armazenamento. A cor $\left(\mathrm{L}^{*}, \mathrm{a}^{*}, \mathrm{~b}^{*}\right)$ da casca foi determinada em espectrofotômetro MiniScan ${ }^{\circledR} \mathrm{EZ}$ marca HunterLab, sendo realizadas cinco leituras por fruto. $\mathrm{O}$ valor de $\mathrm{L}^{*}$ define a luminosidade $\left(\mathrm{L}^{*}=0\right.$ preto e $\mathrm{L}^{*}=100$ branco) e $\mathrm{a}^{*} \mathrm{e} \mathrm{b}^{*}$ são responsáveis pela cromaticidade $\left(+a^{*}\right.$ vermelho e $-a^{*}$ verde $), b^{*}$ $\left(+b^{*}\right.$ amarelo e $-b^{*}$ azul). Por meio do módulo $L^{*}, a^{*}$ $\mathrm{e}^{*}$ foi possível calcular o incremento no escurecimento $\left[\left(\left(L^{*}-L^{*} 0\right)^{2}+\left(a^{*}-a^{*} 0\right)^{2}+\left(b^{*}-b^{*} 0\right)^{2}\right)^{1 / 2}\right]$, croma (saturação ou intensidade da cor; 0 - cor impura e 60
- cor pura) e o ângulo hue (ângulo da cor; $0^{\circ}$ vermelho; $90^{\circ}$ amarelo; $180^{\circ}$ verde; $270^{\circ}$ azul e $360^{\circ}$ negro) por meio das fórmulas: croma $\left[\left(\mathrm{a}^{2}+\mathrm{b}^{2}\right)^{1 / 2}\right]$ e ângulo hue [arco tangente $(\mathrm{b} / \mathrm{a})]$ para $\mathrm{a}^{*}$ positivo e [arco tangente $\left.\left(b^{*} / a^{*}\right)(-1)+90\right]$ para $a^{*}$ negativo, conforme recomendado por Hunterlab (2008).

A textura também foi avaliada na casca dos frutos utilizando-se o texturômetro da marca Brookfield texture Analyzer, modelo CT3 4500. A análise consistiu no teste de resistência de perfuração (teste normal), sendo adotados os padrões de Trigger (força): $10 \mathrm{~g}$, Deformation (deformação): $10 \mathrm{~mm}$ e Speed (velocidade): $10 \mathrm{~mm} / \mathrm{s}$ com o auxilio da ponteira TA 17 , Cone $30 \mathrm{~mm}, \mathrm{D} 45^{\circ}$. Os resultados foram expressos em Newton $(\mathrm{N})$.

As análises de $\mathrm{pH}$, acidez titulável, sólidos solúveis e Ratio foram realizadas na polpa dos frutos de $P$. cincinnata de acordo com Carvalho et al. (1990).

\section{Delineamento experimental e análise estatística}

O delineamento experimental adotado foi o inteiramente casualizado com três repetições, sendo que cada repetição consistiu em seis frutos de $P$. cincinnata. Para as análises de cor e textura foram realizadas três leituras em cada fruto. Antes das análises fisiológicas, os frutos foram avaliados quanto à incidência (\%) de patógenos fúngicos na casca. $\mathrm{O}$ percentual médio de frutos infectados foi calculado para cada tratamento em todas as datas de avaliação. Os dados foram submetidos à análise de variância e comparação de médias pelo teste de Tukey a $1 \%$ de probabilidade, utilizando-se o Software Sisvar (Ferreira, 2019).

\section{Resultados e Discussão}

Na Tabela 1 estão apresentados os valores da caracterização física realizada nos frutos de $P$. cincinnata após a colheita. O diâmetro menor médio dos frutos foi de $63,57 \mathrm{~mm}$ e o diâmetro maior (distância do ápice ao início do pedúnculo) foi de $66,08 \mathrm{~mm}$. Segundo Araújo et al. (2019) a massa dos frutos de $P$. cincinnata varia de 109 g a 212 g. O valor médio $(129,25 \mathrm{~g})$ obtido no presente experimento corresponde à faixa citada pelos autores. A massa dos frutos é uma das características mais importantes adotado pelos consumidores para avaliar a qualidade (Botelho et al., 
Tabela 1. Valores médios de diâmetros menores, diâmetros maiores, massa do fruto, massa da casca, rendimento de casca, massa da semente, rendimento de semente, massa da polpa e rendimento de polpa de frutos de $P$. cincinnata produzidos no campo experimental da Embrapa Cerrados

\begin{tabular}{lc}
\hline $\begin{array}{c}\text { Variáveis físicas } \\
\text { avaliadas nos frutos }\end{array}$ & $\begin{array}{c}\text { Valores médios } \\
\text { obtidos }\end{array}$ \\
\hline Diâmetro menor (mm) & 63,57 \\
Diâmetro maior (mm) & 66,08 \\
Massa do fruto (g) & 129,25 \\
Massa da casca (g) & 51,84 \\
Percentual de casca (\%) & 40,21 \\
Massa da semente (g) & 33,20 \\
Percentual de semente (\%) & 25,72 \\
Massa da polpa (g) & 44,21 \\
Rendimento em polpa (\%) & 34,07 \\
\hline
\end{tabular}

2019). A massa da casca apresentou um valor de 51,84 g correspondendo a 40,21\% da massa fresca total do fruto. Assim, sugere-se que sejam desenvolvidos trabalhos com o objetivo de verificar a possibilidade de utilização da casca de frutos desta espécie para alimentação humana e/ou animal. Uma das alternativas é a possibilidade de produção de pectina, como já realizado com as cascas dos frutos de maracujá azedo. Os frutos desta espécie possuem quantidade considerável de sementes em estado fresco com massa total média de 33,20 g correspondendo a $25,72 \%$ da massa fresca total do fruto. A massa média da polpa sem sementes é de 44,21 g que corresponde a 34,07\% da massa fresca total do fruto. O resultado está de acordo com o valor citado por Araújo et al. (2019) onde afirmam que o rendimento da polpa varia em torno de $35 \%$, quando extraída manualmente em peneira, e de $50 \%$, quando extraída em despolpadora rotativa.

Os valores de $\mathrm{pH}$ estiveram entre 2,73 e 3,16 durante todo o período de armazenamento com valores iniciais de 2,97 (Tabela 2). De acordo com a legislação brasileira (Brasil, 2018) a faixa mínima de $\mathrm{pH}$ para as polpas de maracujá em geral é de 2,7. Assim, os valores obtidos para esta variável em frutos de maracujá da espécie $P$. cincinnata estão em conformidade com os padrões exigidos pela indústria de alimentos. Paula et al. (2017) obtiveram valor médio de 2,8 para esta variável em frutos maduros da mesma espécie correspondendo a faixa de $\mathrm{pH}$ observado neste trabalho. Baixos valores de $\mathrm{pH}$ são desejados em alimentos sendo que esta variável é estabelecida como atributo de qualidade do produto pela legislação, evitando o crescimento de microrganismos e, consequentemente, favorecendo a conservação da polpa (Lira Júnior et al., 2005).

Os tratamentos não influenciaram nos valores de $\mathrm{pH}$, com exceção do tratamento testemunha refrigerado (TR) que apresentou valor de $\mathrm{pH}$ inferior ao mesmo tratamento mantido em condição ambiente (TA) e cera ambiente (CA). Frutos mantidos no tratamento testemunha refrigerado também apresentaram oscilação nos valores de $\mathrm{pH}$ durante o armazenamento, com maiores valores aos 60 e 98 dias de armazenamento. $\mathrm{O}$ aumento dos valores de $\mathrm{pH}$ pode ocorrer devido a formação de ácidos orgânicos e açúcares totais reduzindo a quantidade de íons de hidrogênio livres (D’Abadia et al., 2020).

Os valores de acidez oscilaram entre 2,94 e 4,90 g de ácido cítrico anidro $/ 100 \mathrm{ml}$ de polpa com valores iniciais de 4,13 . Frutos mantidos sob refrigeração apresentaram maiores valores de acidez durante todo o período de armazenamento, não havendo variação significativa para esta variável no tratamento em que os frutos foram revestidos com cera de carnaúba, e mantidos sob refrigeração (CR) (Tabela 2). Os resultados comprovam que no armazenamento em temperatura reduzida ocorre menor atividade metabólica nos frutos, resultando em menor consumo de ácidos orgânicos nos processos metabólicos. As variações observadas nos demais tratamentos também podem ser atribuídas ao fato de a acidez estar correlacionada diretamente a fatores externos, tais como clima, solo, tempo de maturação do fruto e outros (Leal, Reis e Luz, 2013).

Uma das vantagens observadas na polpa dos frutos de $P$. cincinnata são o alto teor de ácido cítrico, sendo apropriada para o processamento na fabricação de geleias, sucos, doces e outros produtos de alto valor agregado (Araújo et al., 2019). Para a industrialização, é importante que os frutos apresentem elevada acidez titulável, diminuindo a adição de acidificantes e propiciando melhoria nutricional, segurança alimentar e qualidade sensorial (Campos et al., 2013). Além disso, frutos mais ácidos são, naturalmente, mais estáveis quanto à deterioração e à proporção relativa de ácidos orgânicos presentes (Almeida, Silva e Gonçalves, 2018). Para os padrões de identidade e qualidade (PIQ), para o maracujá em geral, a acidez mínima deve ser 
Tabela 2. Valores médios de pH, acidez titulável, sólidos solúveis, Ratio, textura e perda de massa fresca em frutos de $P$. cincinnata submetidos a diferentes tratamentos

\begin{tabular}{|c|c|c|c|c|c|c|}
\hline \multicolumn{7}{|c|}{ pH } \\
\hline Tratamentos & $\mathbf{0}$ & 30 & 45 & 60 & 75 & 98 \\
\hline TA & $2,97 \mathrm{aA}$ & $2,92 \mathrm{aA}$ & $3,00 \mathrm{aA}$ & 3,16 aA & 3,14 aA & NA \\
\hline TR & $2,97 \mathrm{aAB}$ & $2,86 \mathrm{aAB}$ & $2,88 \mathrm{aAB}$ & $3,06 \mathrm{aA}$ & $2,73 \mathrm{bB}$ & $3,02 \mathrm{aA}$ \\
\hline $\mathrm{CA}$ & $2,97 \mathrm{aA}$ & $2,86 \mathrm{aA}$ & $2,97 \mathrm{aA}$ & $3,07 \mathrm{aA}$ & $3,08 \mathrm{aA}$ & NA \\
\hline CR & $2,97 \mathrm{aA}$ & 2,96 aA & 2,89 aA & $2,95 \mathrm{aA}$ & $2,95 \mathrm{abA}$ & $3,10 \mathrm{aA}$ \\
\hline \multicolumn{7}{|c|}{ Acidez titulável (g de ácido cítrico anidro/100ml) } \\
\hline $\mathrm{TA}$ & $4,13 \mathrm{aA}$ & $3,74 \mathrm{aAB}$ & $2,95 \mathrm{bB}$ & $2,94 \mathrm{bB}$ & $3,15 \mathrm{bAB}$ & NA \\
\hline TR & $4,13 \mathrm{aAB}$ & $3,86 \mathrm{aAB}$ & $3,46 \mathrm{abB}$ & $3,38 \mathrm{abB}$ & $4,90 \mathrm{aA}$ & 3,78 aAB \\
\hline $\mathrm{CA}$ & $4,13 \mathrm{aA}$ & $3,56 \mathrm{aAB}$ & $2,96 \mathrm{bB}$ & $3,09 \mathrm{abAB}$ & $3,07 \mathrm{bAB}$ & NA \\
\hline $\mathrm{CR}$ & $4,13 \mathrm{aA}$ & $4,04 \mathrm{aA}$ & $4,15 \mathrm{aA}$ & $4,10 \mathrm{aA}$ & $3,58 \mathrm{bA}$ & $3,72 \mathrm{aA}$ \\
\hline \multicolumn{7}{|c|}{ Sólidos solúveis $\left({ }^{\circ} \mathrm{Brix}\right)$} \\
\hline TA & $9,87 \mathrm{aA}$ & 9,73 aA & $8,83 \mathrm{aA}$ & $8,97 \mathrm{aA}$ & $8,33 \mathrm{bA}$ & NA \\
\hline TR & $9,87 \mathrm{aA}$ & $9,57 \mathrm{aA}$ & $9,53 \mathrm{aA}$ & $8,60 \mathrm{aA}$ & $10,13 \mathrm{aA}$ & $8,80 \mathrm{aA}$ \\
\hline CA & $9,87 \mathrm{aA}$ & 9,47 aA & $8,90 \mathrm{aA}$ & $8,63 \mathrm{aA}$ & $8,50 \mathrm{abA}$ & NA \\
\hline $\mathrm{CR}$ & $9,87 \mathrm{aA}$ & $9,93 \mathrm{aA}$ & $9,97 \mathrm{aA}$ & 9,47 aA & $8,63 \mathrm{abA}$ & $8,23 \mathrm{aA}$ \\
\hline \multicolumn{7}{|c|}{ Ratio } \\
\hline TA & $2,39 \mathrm{aA}$ & $2,62 \mathrm{aA}$ & $3,00 \mathrm{aA}$ & $2,96 \mathrm{aA}$ & $2,68 \mathrm{aA}$ & NA \\
\hline TR & 2,39 aAB & $2,47 \mathrm{aAB}$ & $2,81 \mathrm{abA}$ & $2,56 \mathrm{abAB}$ & $2,07 \mathrm{bB}$ & $2,37 \mathrm{aAB}$ \\
\hline $\mathrm{CA}$ & $2,39 \mathrm{aB}$ & $2,66 \mathrm{aAB}$ & $3,04 \mathrm{aA}$ & $2,81 \mathrm{abAB}$ & $2,82 \mathrm{aAB}$ & NA \\
\hline $\mathrm{CR}$ & $2,39 \mathrm{aA}$ & $2,48 \mathrm{aA}$ & $2,43 \mathrm{bA}$ & $2,31 \mathrm{bA}$ & $2,41 \mathrm{abA}$ & $2,23 \mathrm{aA}$ \\
\hline \multicolumn{7}{|c|}{ Textura (N) } \\
\hline $\mathrm{TA}$ & $35,00 \mathrm{aA}$ & $11,60 \mathrm{bB}$ & $5,20 \mathrm{bB}$ & $4,80 \mathrm{bB}$ & $7,70 \mathrm{cB}$ & NA \\
\hline TR & $35,00 \mathrm{aA}$ & $28,20 \mathrm{aAB}$ & $23,80 \mathrm{aABC}$ & $15,36 \mathrm{abC}$ & $26,70 \mathrm{aABC}$ & $20,80 \mathrm{aBC}$ \\
\hline $\mathrm{CA}$ & $35,00 \mathrm{aA}$ & $27,30 \mathrm{aAB}$ & $9,50 \mathrm{bC}$ & $13,76 \mathrm{abBC}$ & $13,80 \mathrm{bcBC}$ & NA \\
\hline $\mathrm{CR}$ & $35,00 \mathrm{aA}$ & $33,60 \mathrm{aA}$ & $27,20 \mathrm{aA}$ & $22,41 \mathrm{aA}$ & $24,60 \mathrm{abA}$ & $25,10 \mathrm{aA}$ \\
\hline \multicolumn{7}{|c|}{ Perda de massa fresca $(\%)$} \\
\hline TA & $0,00 \mathrm{aE}$ & $5,48 \mathrm{aD}$ & $12,13 \mathrm{aC}$ & $25,36 \mathrm{aB}$ & $45,07 \mathrm{aA}$ & NA \\
\hline TR & $0,00 \mathrm{aA}$ & $1,86 \mathrm{aA}$ & 3,15 aA & $4,38 \mathrm{cA}$ & $5,66 \mathrm{cA}$ & 7,89 aA \\
\hline $\mathrm{CA}$ & $0,00 \mathrm{aB}$ & $2,78 \mathrm{aB}$ & $5,42 \mathrm{aB}$ & $10,91 \mathrm{bAB}$ & $21,63 \mathrm{bA}$ & NA \\
\hline CR & $0,00 \mathrm{aA}$ & $0,24 \mathrm{aA}$ & $1,61 \mathrm{aA}$ & $2,25 \mathrm{cA}$ & $2,94 \mathrm{cA}$ & $4,61 \mathrm{aA}$ \\
\hline
\end{tabular}

Letras minúsculas iguais, na mesma coluna, não diferem significativamente ao nível de $1 \%$ no teste de Tukey. Letras maiúsculas iguais, na mesma linha, não diferem significativamente ao nível de $1 \%$ no teste de Tukey. TA: Testemunha Ambiente; TR: Testemunha Refrigerado; CA: Cera Ambiente; CR: Cera Refrigerado.

NA: Não Analisado devido a 100\% de contaminação fúngica.

de 2,50\%. Os resultados de acidez titulável obtidos no presente trabalho na polpa dos frutos de $P$. cincinnata estão acima do valor mínimo exigido.

Os valores de sólidos solúveis estiveram entre 8,23 ${ }^{\circ}$ Brix e $10,13{ }^{\circ}$ Brix correspondendo à concentração de sólidos solúveis para a espécie, onde segundo Araújo et al. (2019), os valores variam de $8{ }^{\circ}$ Brix a $13^{\circ}$ Brix. Entretanto, a legislação brasileira estabelece o valor mínimo de $11^{\circ}$ Brix para a polpa de frutos de maracujá em geral (BRASIL, 2000). A variável sólidos solúveis é utilizada como indicadora na qualidade de frutos destinados à indústria, com uma preferência por frutos com teores de sólidos solúveis superiores a $13^{\circ}$ Brix (Bruckner et al., 2002). Santos (2018) obteve o valor máximo de $12,0{ }^{\circ}$ Brix ao estudar a fisiologia do amadurecimento de frutos de $P$. cincinnata, com o 
objetivo de avaliar o desenvolvimento e a fisiologia da maturação dos frutos, visando à indicação do ponto de colheita. O valor máximo obtido por D'Abadia et al. (2020) foi de $12,90{ }^{\circ}$ Brix em frutos de $P$. cincinnata também com 100 dias após a antese.

Os valores de Ratio variaram de 2,07 a 3,04 correspondendo aos valores de sólidos solúveis e acidez titulável (Tabela 2). De acordo com Aguiar et al. (2015), o equilíbrio entre sólidos solúveis e acidez titulável é uma das formas mais práticas de estimar o sabor dos frutos, sendo que com a acidez titulável alta, o Ratio diminui e, quanto maior for o Ratio, mais agradável ao paladar é o suco ou polpa. Essa variável expressa à doçura relativa do produto e é utilizada para indicar a maturidade pela indústria de processamento de frutos tropicais (Askar \& Treptow, 1993).

Para a indústria de sucos de maracujá, o Ratio de 3,5 a 4,7 em maracujá amarelo confere maior palatabilidade ao produto (Nagato et al., 2003). Estes valores estão bem acima do observado no presente trabalho devido à maior acidez do maracujá $P$. cincinnata em relação ao amarelo (Pita, 2012). No entanto, do ponto de vista industrial, o elevado teor de acidez diminui a necessidade de adição de acidificantes e propicia melhoria nutricional, segurança alimentar e qualidade sensorial (Rocha et al., 2001).

A textura dos frutos mantidos sob refrigeração foi significativamente maior que a dos mantidos em condição ambiente. Frutos com aplicação de cera de carnaúba a $18 \%$ mantidos sob refrigeração (CA) mantiveram a textura inicial durante os 98 dias de armazenamento (Tabela 2) não diferindo dos frutos mantidos apenas sob refrigeração (TR). A manutenção da textura dos frutos durante o armazenamento é essencial comprovando a menor perda de massa fresca e atividade metabólica uma vez que, em geral, a firmeza diminui com a maturação do fruto (Sams, 1999). A utilização da cera de carnaúba a $18 \%$ nos frutos mantidos em condição ambiente não foi efetiva na manutenção da textura dos frutos de P. cincinnata. A concentração de cera utilizada não foi o suficiente para a redução da atividade metabólica dos frutos mantidos em condição ambiente. Sugerem-se novos estudos com diferentes concentrações do produto de forma a concluir se o produto pode ser efetivo na manutenção da vida útil dos frutos de $P$. cincinnata sem refrigeração.
A perda de massa fresca dos frutos de $P$. cincinnata também foi menor nos frutos mantidos sob refrigeração independente da utilização de cera de carnaúba. A cera de carnaúba aliada à refrigeração (CR) também auxiliou na redução desta variável. Frutos com aplicação de cera de carnaúba mantidos refrigerados (CR) apresentaram baixa perda de massa fresca atingindo $4,61 \%$ aos 98 dias de armazenamento (Tabela 2). A aplicação de cera de carnaúba tem o objetivo de melhorar a aparência e diminuir a taxa de transpiração dos frutos, o que reduz a perda de massa fresca, permitindo vida útil mais prolongada e conservação da sua firmeza (Genú e Pinto, 2002).

Mesmo com a polpa em boas condições de consumo, a perda de massa é considerada fator limitante para a conservação de frutos de maracujazeiro, sendo que a murcha e o enrugamento da casca causam a depreciação dos frutos, principalmente para a comercialização in natura (Rotili et al., 2013b). Segundo a FAEP (2003), frutos de maracujazeiro são considerados murchos a partir de uma perda de massa fresca de $8 \%$ do seu peso inicial. Neste estudo frutos mantidos sob refrigeração mantiveram perda de massa fresca inferior a $8 \%$ durante os 98 dias de armazenamento. Frutos com aplicação de cera mantida em ambiente natural (CA) apresentam porcentagem aceitável de perda de massa fresca até os 45 dias de armazenamento. Já os frutos somente mantidos em condição ambiente (TA) apresentam aceitabilidade somente até 30 dias de armazenamento. A baixa concentração (18\%) da cera de carnaúba utilizada no presente trabalho pode ter sido o fator responsável pelo baixo efeito na vida útil dos frutos de $P$. cincinnata no presente trabalho.

Baixas temperaturas são fundamentais na redução da perda de massa fresca em frutos de maracujá (Rinaldi et al., 2017a; Rinaldi et al., 2017b; Rinaldi et al., 2019a; Rinaldi et al., 2019b), revestidos com cera e filmes plásticos (Moura et al., 2016) e com o uso de atmosfera modificada (Favorito et al., 2017).

Os valores de luminosidade variaram entre 44,16 e 58,81 , comprovando que os frutos de $P$. cincinnata não podem ser considerados como frutos de cor clara (Tabela 3). Maiores valores de luminosidade indicam que os produtos são mais claros (AMSAM, 2012). Os valores de $\mathrm{a}^{*}$ foram negativos em todos os tratamentos, sendo que valores negativos de a* correspondem à cor verde que é característica de frutos de P. cincinnata. 
Tabela 3. Valores médios de $\mathrm{L}^{*}, \mathrm{a}^{*}, \mathrm{~b}^{*}$, incremento de escurecimento, croma, ângulo hue em frutos de $P$. cincinnata submetidos a diferentes tratamentos

\begin{tabular}{|c|c|c|c|c|c|c|}
\hline \multicolumn{7}{|c|}{$\mathbf{L}^{*}$} \\
\hline \multicolumn{7}{|c|}{ Dias de armazenamento } \\
\hline Tratamentos & $\mathbf{0}$ & 30 & 45 & 60 & 75 & 98 \\
\hline TA & $46,74 \mathrm{aB}$ & $58,03 \mathrm{aA}$ & $58,81 \mathrm{aA}$ & $57,96 \mathrm{aA}$ & $52,82 \mathrm{abAB}$ & NA \\
\hline TR & $46,74 \mathrm{aA}$ & $48,51 \mathrm{bA}$ & $49,89 \mathrm{bcA}$ & $48,12 \mathrm{cA}$ & $49,24 \mathrm{abA}$ & $53,55 \mathrm{aA}$ \\
\hline $\mathrm{CA}$ & $46,74 \mathrm{aB}$ & $49,68 \mathrm{bAB}$ & $55,97 \mathrm{abA}$ & $54,90 \mathrm{abA}$ & $54,36 \mathrm{aA}$ & NA \\
\hline $\mathrm{CR}$ & $46,74 \mathrm{aA}$ & 44,16 bA & $46,65 \mathrm{cA}$ & $49,60 \mathrm{bcA}$ & $46,70 \mathrm{bA}$ & $50,27 \mathrm{aA}$ \\
\hline \multicolumn{7}{|c|}{$\mathbf{a}^{*}$} \\
\hline TA & $-8,90 \mathrm{aC}$ & $-4,17 \mathrm{aBC}$ & $-2,56 \mathrm{aABC}$ & $-3,92 \mathrm{aAB}$ & $-2,43$ aABC & NA \\
\hline TR & $-8,90 \mathrm{aA}$ & $-7,40 \mathrm{aA}$ & $-5,32 \mathrm{aA}$ & $-5,09 \mathrm{bA}$ & $-2,59 \mathrm{aA}$ & $-5,62 \mathrm{aA}$ \\
\hline $\mathrm{CA}$ & $-8,90 \mathrm{aA}$ & $-6,56 \mathrm{aA}$ & $-5,70 \mathrm{aA}$ & $-6,45 \mathrm{bA}$ & $-6,44 \mathrm{aA}$ & NA \\
\hline $\mathrm{CR}$ & $-8,90 \mathrm{aA}$ & $-7,82$ aA & $-6,73 \mathrm{aA}$ & $-5,18 \mathrm{bA}$ & $-6,01 \mathrm{aA}$ & $-5,45$ aA \\
\hline \multicolumn{7}{|c|}{$\mathbf{b}^{*}$} \\
\hline TA & $27,20 \mathrm{aB}$ & $35,48 \mathrm{aAB}$ & 36,29 aA & $30,53 \mathrm{abAB}$ & $30,59 \mathrm{abAB}$ & NA \\
\hline TR & $27,20 \mathrm{aA}$ & $27,59 \mathrm{abA}$ & $29,37 \mathrm{abA}$ & $25,61 \mathrm{bA}$ & $27,78 \mathrm{bA}$ & 31,96 aA \\
\hline $\mathrm{CA}$ & $27,20 \mathrm{aAB}$ & $26,42 \mathrm{bB}$ & $34,24 \mathrm{aAB}$ & $35,26 \mathrm{aAB}$ & $36,00 \mathrm{aA}$ & NA \\
\hline $\mathrm{CR}$ & $27,20 \mathrm{aA}$ & $24,34 \mathrm{bA}$ & $25,95 \mathrm{bA}$ & $27,67 \mathrm{abA}$ & $24,78 \mathrm{bA}$ & 28,76 aA \\
\hline \multicolumn{7}{|c|}{ Incremento de escurecimento } \\
\hline TA & $0,00 \mathrm{aD}$ & $18,65 \mathrm{aBC}$ & $25,68 \mathrm{aA}$ & $24,17 \mathrm{aAB}$ & $15,95 \mathrm{bC}$ & NA \\
\hline TR & $0,00 \mathrm{aC}$ & $12,11 \mathrm{bB}$ & $14,31 \mathrm{bcB}$ & $14,54 \mathrm{bB}$ & $29,13 \mathrm{aA}$ & $15,12 \mathrm{aB}$ \\
\hline $\mathrm{CA}$ & $0,00 \mathrm{aC}$ & $13,16 \mathrm{abB}$ & $19,59 \mathrm{abAB}$ & $21,58 \mathrm{aA}$ & $14,92 \mathrm{bAB}$ & NA \\
\hline $\mathrm{CR}$ & $0,00 \mathrm{aC}$ & $11,83 \mathrm{bB}$ & $11,86 \mathrm{cB}$ & $14,02 \mathrm{bB}$ & $31,89 \mathrm{aA}$ & $12,78 \mathrm{aB}$ \\
\hline \multicolumn{7}{|c|}{ Croma } \\
\hline TA & $28,70 \mathrm{aA}$ & $35,87 \mathrm{aA}$ & $37,02 \mathrm{aA}$ & $31,51 \mathrm{abA}$ & $31,53 \mathrm{abA}$ & NA \\
\hline TR & $28,70 \mathrm{aA}$ & $28,67 \mathrm{abA}$ & $30,40 \mathrm{abA}$ & 26,38 bA & $28,84 \mathrm{abA}$ & $32,68 \mathrm{aA}$ \\
\hline $\mathrm{CA}$ & $28,70 \mathrm{aA}$ & $27,38 \mathrm{bA}$ & $34,88 \mathrm{abA}$ & $36,08 \mathrm{aA}$ & $34,76 \mathrm{aA}$ & NA \\
\hline $\mathrm{CR}$ & $28,70 \mathrm{aA}$ & $25,63 \mathrm{bA}$ & 27,02 bA & $28,39 \mathrm{abA}$ & $25,59 \mathrm{bA}$ & $29,40 \mathrm{aA}$ \\
\hline \multicolumn{7}{|c|}{ Ângulo hue } \\
\hline TA & $91,24 \mathrm{aA}$ & $89,96 \mathrm{aAB}$ & 81,96 bBC & $76,72 \mathrm{cC}$ & $78,68 \mathrm{bC}$ & NA \\
\hline TR & $91,24 \mathrm{aA}$ & $91,30 \mathrm{aA}$ & $89,43 \mathrm{abA}$ & $97,62 \mathrm{aA}$ & $91,30 \mathrm{aA}$ & $89,74 \mathrm{aA}$ \\
\hline $\mathrm{CA}$ & $91,24 \mathrm{aA}$ & $91,03 \mathrm{aA}$ & $88,02 \mathrm{abA}$ & $84,51 \mathrm{bA}$ & $84,36 \mathrm{abA}$ & NA \\
\hline $\mathrm{CR}$ & $91,24 \mathrm{aA}$ & $91,25 \mathrm{aA}$ & $90,60 \mathrm{aA}$ & $88,61 \mathrm{bA}$ & $91,25 \mathrm{aA}$ & $90,85 \mathrm{aA}$ \\
\hline
\end{tabular}

Letras minúsculas iguais, na mesma coluna, não diferem significativamente ao nível de $1 \%$ no teste de Tukey.

Letras maiúsculas iguais, na mesma linha, não diferem significativamente ao nível de 1\% no teste de Tukey.

TA: Testemunha Ambiente; TR: Testemunha Refrigerado; CA: Cera Ambiente; CR: Cera Refrigerado.

NA: Não Analisado devido a 100\% de contaminação fúngica.

Dessa forma, os valores de luminosidade também correspondem à cor real dos frutos desta espécie. D'Abadia et al. (2020) também afirmam que os frutos de $P$. cincinnata não apresentam alteração na sua coloração, permanecendo com a casca verde mesmo quando maduros, o que confirma os valores de luminosidade e a* obtidos no presente experimento.
A mudança de cor da casca é uma das transformações fisiológicas pela qual o fruto passa e que altera as suas características físico-químicas ao longo do amadurecimento (Botelho et al., 2019). Em frutos de $P$. cincinnata a coloração permanece por um longo período sem modificações, o que é desejável no processo de armazenamento e comercialização, 
mas dificulta a identificação visual do ponto de colheita do fruto (Santos, 2018).

Os valores de $b^{*}$ estiveram entre 24,34 e 36,29 , sendo que valores positivos de $\mathrm{b}^{*}$ significam frutos de cor amarela ou tendência ao amarelo. De maneira geral, frutos mantidos sob refrigeração apresentaram menores valores de $b^{*}$, o que significa que houve a manutenção da cor inicial nestes frutos sem ocorrência de alterações significativas (Tabela 3).

Os valores de incremento no escurecimento foram menores nos frutos mantidos sob refrigeração, não havendo influência da cera de carnaúba nos frutos mantidos sob condição ambiente. De acordo com os valores de $L^{*}, a^{*}$ e $b^{*}$, não é possível afirmar que houve escurecimento nestes frutos durante $o$ armazenamento. Visualmente a mudança de cor ocorreu com tendência ao clareamento dos frutos, com um leve aparecimento da cor amarela mais ao final do período de armazenamento. Dessa forma, o variável incremento no escurecimento não apresenta bons resultados na avaliação de frutos de $P$. cincinnata durante o armazenamento, não sendo recomendada para a análise de frutos desta espécie.

Quanto ao croma, valores de saturação de cor próximos a zero indicam cores neutras (cinza), enquanto próximos de 60 implicam cores intensas ou vívidas (Jacomino, Mendonça e Kluge, 2003). O índice de saturação (croma) expressa à intensidade da cor, ou seja, a cor em termos de saturação de pigmentos, sendo 0 - cor impura e 60 - cor pura (Rinaldi et al., 2017b). No presente trabalho os valores de croma estiveram entre 25,59 e 37,02, não havendo diferença significativa nos frutos submetidos ao mesmo tratamento durante os 98 dias de armazenamento. A cera de carnaúba também não apresentou influência sobre esta variável, podendo ser devido à concentração, forma de aplicação, atividade metabólica do fruto e outros.

Quanto ao ângulo hue, ocorreu redução significativa somente nos frutos submetidos à temperatura ambiente sem aplicação de cera de carnaúba a partir dos 45 dias em relação aos valores obtidos no início do armazenamento. Esta variável de tonalidade expressa às diferenças na coloração da casca, permitindo visualizar a mudança na cor dos frutos, de verde para amarela (Azzolini, Jacomino e Bron, 2004) sendo que valores próximos de zero tendem à cor vermelha. Mais próximo de $90^{\circ}$, há maior predominância da cor amarela (Alves et al., 2008). Os menores valores de ângulo hue foram obtidos nos frutos mantidos sob condição ambiente o que já era esperado. A utilização da cera de carnaúba não foi efetiva na manutenção da cor dos frutos de $P$. cincinnata.

Existem, na literatura, vários relatos de fungos fitopatogênicos infectando frutos de diferentes espécies de Passiflora, entre eles Collethotrichum spp. e Fusarium spp. (Junqueira et al., 2003; Rinaldi et al., 2017c). No entanto, no presente experimento, um único patógeno causou sintomas de podridão mole nos frutos de $P$. cincinnata. A sintomatologia, com lesões úmidas e de coloração marrom-clara, e os sinais do fungo, um mofo branco e enrugado, de aspecto cremoso, são similares à podridão azeda, causada pelo fungo Geotrichum candidum (Suprapta, Arai e Iwai, 1995). Frutos com lesões foram detectados inicialmente nos tratamentos armazenados em temperatura ambiente na avaliação aos 30 dias (Tabela 4). Nos tratamentos sob refrigeração, os primeiros frutos com podridão mole apareceram aos 45 dias e somente no tratamento com cera de carnaúba podendo ser devido as próprias características do produto testado. O tratamento controle sob refrigeração só apresentou frutos com

Tabela 4. Valores médios de incidência de podridão mole em frutos de P. cincinnata submetidos a diferentes tratamentos

\begin{tabular}{ccccccc}
\hline \multicolumn{7}{c}{ Valor médio de frutos infestados (\%) } \\
\hline Tratamentos & $\mathbf{0}$ & $\mathbf{3 0}$ & $\mathbf{4 5}$ & $\mathbf{6 0}$ & $\mathbf{7 5}$ & $\mathbf{9 8}$ \\
\hline TA & $0 \mathrm{aA}$ & $8,34 \mathrm{aA}$ & $41,67 \mathrm{aB}$ & $75 \mathrm{aBC}$ & $83,34 \mathrm{aCD}$ & $100 \mathrm{aCD}$ \\
TR & $0 \mathrm{aA}$ & $0 \mathrm{aA}$ & $0 \mathrm{bA}$ & $0 \mathrm{cA}$ & $0 \mathrm{bA}$ & $16,67 \mathrm{bA}$ \\
CA & $0 \mathrm{aA}$ & $8,34 \mathrm{aA}$ & $16,67 \mathrm{abAB}$ & $41,67 \mathrm{abBC}$ & $66,67 \mathrm{aCD}$ & $100 \mathrm{aD}$ \\
CR & $0 \mathrm{aA}$ & $0 \mathrm{aA}$ & $16,67 \mathrm{abA}$ & $16,67 \mathrm{bcA}$ & $16,67 \mathrm{bA}$ & $16,67 \mathrm{bA}$ \\
\hline
\end{tabular}

Letras minúsculas iguais, na mesma coluna, não diferem significativamente ao nível de $1 \%$ no teste de Tukey.

Letras maiúsculas iguais, na mesma linha, não diferem significativamente ao nível de $1 \%$ no teste de Tukey.

TA: Testemunha Ambiente; TR: Testemunha Refrigerado; CA: Cera Ambiente; CR: Cera Refrigerado. 
sintomas da doença na última avaliação, aos 98 dias (Tabela 4). Ambos os tratamentos armazenados a temperatura ambiente tiveram todos os frutos infectados ao final do experimento, enquanto os frutos armazenados sob refrigeração, com ou sem cera de carnaúba, tiveram, comparativamente, uma performance significativamente superior (Tabela 4). Os resultados corroboram os relatos de Junqueira et al. (2003), Rinaldi et al. (2019a e 2017a) e Rotili et al. (2013b) sobre a importância da refrigeração na conservação pós-colheita de frutos do gênero Passiflora. Além disso, demonstraram a ineficácia da cera de carnaúba, na concentração estudada, quanto à prevenção de infecções fúngicas.

\section{Conclusões}

Frutos de $P$. cincinnata podem ser mantidos em câmara fria na temperatura de $10{ }^{\circ} \mathrm{C}$ e umidade relativa de $85 \%$ por 98 dias. Em condição de temperatura e umidade relativa de ambiente, a vida útil dos frutos é de no máximo 30 dias.

A utilização da cera de carnaúba na concentração de $18 \%$ não aumenta a vida útil dos frutos de $P$. cincinnata, não justificando a sua utilização.

\section{Agradecimentos}

Os autores agradecem ao Conselho Nacional de Desenvolvimento Científico e Tecnológico (CNPq) projeto $\mathrm{n}^{\circ} 404847 / 2012-09$ pelo apoio financeiro, bolsas de Iniciaçao Científica (PIBIC/CNPQ) e à Empresa Brasileira de Pesquisa Agropecuária (Embrapa) pelo apoio no desenvolvimento deste projeto de pesquisa.

\section{Literatura Citada}

AGUIAR, R. S. et al. 2015. Produção e qualidade de frutos híbridos de maracujazeiro amarelo no norte do Paraná. Revista Brasileira de Fruticultura 37(1):130-137.

ALMEIDA, E. S.; SILVA, R. J. N.; GONÇALVES, E. M. 2018. Compostos fenólicos totais e características físico-químicas de frutos de jabuticaba. Gaia Scientia 12(1):81-89.

ALVES, C. C. O. et al. 2008. Estabilidade da microestrutura e do teor de carotenóides de pós obtidos da polpa de pequi (Caryocar brasiliense Camb.) liofilizada. Food Science and Technology 28:830-839.
AMERICAN MEAT SCIENCE ASSOCIATION MEAT AMSAM. 2012. Meat color measurement guidelines. Savoy: American Meat Science Association.

ARAÚJO, F. P. et al. 2019. Cultivo de Passiflora cincinnata Mast. cv. BRS Sertão Forte. Circular Técnica. Petrolina, PE. 12p.

ASKAR, A.; TREPTOW, H. 1993. Quality assurance in tropical fruit processing. New York: Springer-Verlag, 231p.

AZZOLINI, M.; JACOMINO, A. P.; BRON, I. U. 2004. Índices para avaliar qualidade pós-colheita de goiabas em diferentes estádios de maturação. Pesquisa Agropecuária Brasileira 39(2):139-145.

BLUM, J. et al. 2008. Uso de cera na conservação pós-colheita do caqui cv. Giombo. Revista Brasileira de Fruticultura 30(3):830-833.

BOTELHO, S. C. C. et al. 2019. Qualidade pós-colheita de frutos de maracujazeiro-amarelo colhidos em diferentes estádios de maturação. Revista Ciências Agrárias 62:1-8.

BRASIL, 2000. MINISTÉRIO DA AGRICULTURA E DO ABASTECIMENTO. Diário Oficial da União. Instrução Normativa $n^{\circ} 1$ - Aprova o Regulamento Técnico Geral para fixação dos padrões de identidade de qualidade para polpa de fruta (e suco de fruta). Diário Oficial da União, seção 1, Brasília, DF.

BRASIL, 2018. MINISTÉRIO DA AGRICULTURA E DO ABASTECIMENTO. Diário Oficial da União. Instrução Normativa $n^{\circ} 49$ - Fica estabelecida em todo o território nacional a complementação dos Padrões de Identidade e Qualidade de Suco e Polpa de Fruta, na forma desta Instrução Normativa. Diário Oficial da União, Brasília, DF.

BRUCKNER, C. H. et al. 2002. Maracujazeiro. In: BRUCKNER, C. H. (ed.). Melhoramento de fruteiras tropicais. Viçosa, MG, UFV. 373-410.

CAMPOS, V. B. et al. 2013. Caracterização física e química de frutos de maracujá-amarelo comercializados em Macapá, Amapá. Revista Brasileira de Produtos Agroindustriais 15(1):27-33.

CARMO, T. V. B. et al. 2017. Genetic diversity in accessions of Passiflora cincinnata Mast. based on morphoagronomic descriptors and molecular markers. Revista Caatinga 30(1):68-77.

CARVALHO, C. R. L. et al. 1990. Análises químicas de alimentos. ITAL, 121p.

D'ABADIA, A. C.A. et al. 2020. Determination of the maturation stage and characteristics of the fruits of two populations of Passiflora cincinnata Mast. Revista Caatinga 33(2):349-360.

FEDERAÇÃO DA AGRICULTURA DO ESTADO DO PARANÁ - FAEP. 2003. Maracujá. Federação da Agricultura do Estado do Paraná, Curitiba. Disponível em: http:// www.faep.com.br/comissoes/frutas/cartilhas/frutas/ maracuja.htm. Acesso em: 30 dez. 2020.

Agrotrópica 33(1) 2021 
FALEIRO, F. G. et al. 2017. Espécies de maracujazeiro no mercado internacional. In: Junghans, T. G.; Jesus, O. N. (ed.). Maracujá: do cultivo à comercialização. Brasília, DF, Embrapa.pp.15-37.

FAVORITO, P. A. et al. 2017. Qualidade e conservação póscolheita de frutos de maracujá-amarelo sob armazenamento. Scientia Agraria Paranaensis 16(4):449-453.

FERREIRA, D. F. 2019. Sisvar: a computer analysis system to fixed effects split plot type designs. Revista Brasileira de Biometria 37(4):529-535.

GENÚ, P. J. C. PINTO, A. C. Q. 2002. A Cultura da Mangueira. Embrapa. Informação Tecnológica. Brasília, DF. 479p.

HAGENMAIER, R. D.; BAKER, R. A. 1994. Wax microemulsions and emulsions as citrus coating. Journal of Agricultural and Food Chemistry 42:899-902.

HUNTERLAB, 2008. Insight on color: CIE L*a* b* color scale. Reston. VA, USA.

JACOMINO, A. P.; MENDONÇA, K.; KLUGE, R. A. 2003. Armazenamento refrigerado de limões ‘Siciliano' tratados com etileno. Revista Brasileira de Fruticultura 25(1):45-48.

JUNQUEIRA, N. T. V. et al. 2003. Severidade da antracnose e perda de matéria fresca de frutos de dez procedências de maracujazeiro-doce (Passiflora alata Dryander) em dois ambientes de armazenamento. Revista Brasileira de Fruticultura 25(1):71-73.

LEAL, R. C.; REIS, V. B.; LUZ, D. A. 2013. Avaliação de parâmetros físico-químicos de polpas congeladas de graviola comercializada em supermercados de São Luís, MA. Cadernos de Pesquisa 20(2):76-80.

LIMA, L. A. S. et al. 2014. Caracterização dos solos da Bacia do Sarandi. Planaltina, DF, Embrapa Cerrados. Boletim de Pesquisa e Desenvolvimento 318.47p.

LIRA JÚNIOR, J. S. et al. 2005. Caracterização física e físicoquímica de frutos de cajá-umbu (Spondias spp.). Food Science and Technology 25(4):757-761.

MOTA, W. F. et al. 2006. Uso de cera de carnaúba e saco plástico poliolefínico na conservação pós-colheita do maracujáamarelo. Revista Brasileira de Fruticultura 28(2):190-193.

MOTA, W. F. et al. 2003. Ceras e embalagem plástica na conservação pós-colheita do maracujá-amarelo. Scientia Agricola 60(1):51-57.

MOURA, G. S. et al. 2016. Conservação pós-colheita de frutos de maracujá-amarelo por derivados de capim-limão(Cymbopogon citratus). Ambiência 12(2):667-682.

NAGATO, L. A. F. et al. 2003. Parâmetros físicos e químicos e aceitabilidade sensorial de sucos de frutas integrais, maracujá e uva, de diferentes marcas comerciais brasileiras. Brazilian Journal of Food Technology 1(6):127-136.

NOVAIS JÚNIOR, M. M. et al. 2020. Desenvolvimento de geleia de maracujá do mato (Passiflora cincinnata): caracterização microbiológica, física, química e estudo da estabilidade. Brazilian Journal of Development 6(7):43403-43414.

PAULA, S. G. et al. 2017. Caracterização química de maracujádo-mato cultivado em sistema orgânico. In: $11^{\circ}$ Fórum de Ensino, Pesquisa, Extensão e Gestão - FEPEG. Anais... Montes Claros, MG, Universidade Estadual de Montes Claros, $3 p$.

PITA, J. S. L. 2012. Caracterização físico-química e nutricional da polpa e farinha da casca de maracujazeiro do mato e amarelo. Dissertação Mestrado. Itapetinga, BA. UESB. 80p.

RINALDI, M. M. et al. 2019a. Post-harvest conservation of Passiflora alata fruits under ambient and refrigerated condition. Ciência e Tecnologia de Alimentos 1:1-8.

RINALDI, M. M. et al. 2019b. Atmosfera modificada na conservação pós-colheita de frutos de Passiflora alata cv. BRS Mel do Cerrado (BRS MC). Agrotrópica 31:185-196.

RINALDI, M. M. et al. 2017a. Effect of different packaging materials on the shelf life of passion fruits during ambient and low temperature storage. Journal of Postharvest Technology 5:7-16.

RINALDI, M. M. et al. 2017b. Conservação pós-colheita de frutos de Passiflora setacea DC. submetidos a diferentes sanitizantes e temperaturas de armazenamento. Brazilian Journal of Food and Technology 20:e2016046.

RINALDI, M. M. et al. 2017c. Recomendações de manuseio e conservação pós-colheita de frutos de Passiflora setacea e Passiflora alata. Brasília, DF, Embrapa. Comunicado Técnico. $4 \mathrm{p}$.

ROCHA, M. C. et al. 2001. Efeito do uso de biofertilizante agrobio sobre as características físico-químicas na pós-colheita do maracujá-amarelo (Passiflora edulis $f$. flavicarpa Deg.) no município de Taubaté. Revista Biociências 7(2):7-13.

ROTILI, M. C. C. et al. 2013a. Composição, atividade antioxidante e qualidade do maracujá amarelo durante armazenamento. Semina: Ciências Agrárias 34(1):227-240.

ROTILI, M. C. C. et al. 2013b. Atividade antioxidante, composição química e conservação do maracujá-amarelo embalado com filme PVC. Revista Brasileira Fruticultura 35(4):942-952.

SAMS, C. A. 1999. Preharvest factors affecting postharvest texture. Postharvest Biology and Technology 15:249-254.

SANTOS, J. L. 2018. Fisiologia da maturação de frutos e superação de dormência em sementes de maracujá-do-mato (Passiflora cincinnata Mast.). Tese Doutorado. Vitória da Conquista, BA, UESB. 82p.

SILVA, A. P.; LACERDA, S. A.; VIEITES, R. L. 1999. Conservação pós-colheita do maracujá doce com ceras comerciais. Boletim do Centro de Pesquisa de Processamento de Alimentos (B.CEPPA) 17(2):103-114.

SUPRAPTA, D. N.; ARAI, K.; IWAI, H. 1995. Distribution of Geotrichum candidum citrus race in citrus groves and noncitrus fields in Japan. Mycoscience 36:277-282. 